\title{
I Am Able to Love Myself Again
}

\author{
Aisha Al-Thani \\ Qatar University, Qatar
}

\begin{abstract}
Due to the rapid and major changes that modern life witnesses, our lives turned to be more stressful and disappointing, as a result, many psychoses and illnesses spread among people. Nowadays, depression is one of the most serious illnesses that afflict a large number of people.

According to Gilbert, the term 'depression' comes from the Latin word 'deprimere' meaning 'to press down'. Gilbert says; "Depression affects not only how we feel, but also how we think about things, our energy levels, our concentration, our sleep, even our interests in sex. Depression has an effect on many aspects of our life."

In this article, we are going to reveal the great efforts exerted at Hamad Medical Corporation Hospital (HMC) at the State of Qatar to help and support Muslim clients who suffer from depression, through applying the Person- Centered Approach (PCA).
\end{abstract}

\section{Introduction}

The counsellig orientation was developed by Carl Rogers and was originally known as non-directive, then client-centered therapy. The British Association of Counselling and therapy has identified it as follows: "....Counselling takes place when a counsellor sees a client in a private and confidential setting to explore a difficulty the client is having, distress they may be experiencing or perhaps their dissatisfaction with life, or loss of a sense of direction and purpose... Counselling is a way of enabling choice or change or of reducing confusion. It does not involve giving advice or directing a client to take a particular course of action. ....." [3].

According to Rogers, a client needs to be helped by the counselor to feel safe and accepted during the counseling session. Howe agrees with Rogers, he believes that a client needs to feel safe and secure within the therapeutic relationships. Baldwin [2] assured that discovering the self helps both the client and the counselor to be aware of the selfrelationship.

Here, I am going to present one of the most interesting depressed cases I worked with in 2007 at
Hamad Medical Corporation (HMC) during my PhD journey. We will witness the effect of applying a modification to the PCA in helping and supporting a Muslim client. Moreover, we will highlight the positive changes that the case went through during the PCA counseling sessions and explain the positive outcomes of integrating the Islamic values with the PCA in the context of a depressed Muslim client.

The study case is about Fatma, a 42-year-old Egyptian married woman with four daughters and a son; her GP referred her to HMC as she was suffering from depression and had been on medication since 2004. Fatma had never had counselling support prior to meeting me and our first session took place in 2007.

Fatma came from a very strict religious background. She was brought up in an Islamic environment surrounded by her father's teachings; who was a religious imam and had an outstanding social status in his society. Fatma- my client- had a happy childhood until the death of her father while she was at secondary school. The father had been the closest person to her heart and she loved him dearly. The death of the father changed Fatma's life dramatically and brought her many problems, especially when her widowed mother started to depend on her take on the family responsibilities, as she was the eldest child of the family.

Suddenly, she found herself departing her childhood and turning to be someone who had to take care of everything around her; including her mother, siblings, and herself.

The client received fourteen videoed counseling sessions plus two feedback interviews.

In the first session, the client did not know how or where to begin, as everything she had previously dreamed of had changed. Eventually she started to talk about her brother, with whom she had a very strong relationship and who meant everything to her, especially since the death of her father. When their father died her brother was only six years old, and Fatma had been responsible for caring for him ever since. After his graduation, Fatma's brother, Mohammed, travelled abroad to live with her and find a job. Fatma had hoped that he could eventually take her father's place and take care of the whole family, but her dreams were destroyed when a car 
accident in 2003 disabled the brother. She started her first session talking about him and how badly this incident had affected her:

"I don't know where to start ... At the beginning or at the end ... because the end that I'm living now is more tragic. The thing that brought the issue to a head was the accident that happened to my brother and my husband. My husband was the driver when it happened, and his injuries were not serious, but my brother's injury was a serious one to his head. He had to stay for some time in the hospital, He was a pharmacist and I had great hopes for him, but I was shocked by this accident. (Session 1)

During session 2 Fatma told me of her feelings following her first session with me. She had spent the whole week before our second session searching for herself. She had realized that she had talked about her issues with others but was not aware of herself. Our counselling journey began when Fatma became aware that she had lost track of who she was:

"Where is Fatma in all of this? The whole week I sat thinking ... Comparing the attitudes that harmed me ... where am I? ... I am there in every picture. I discovered that I forget myself [falls silent]".

In session 4, Fatma expressed her desire to have a happy life and work towards eliminating her unwanted memories. This indicates that she had started thinking more positively about her life as a whole. Fatma remembered her fiancé, who was also her cousin, attitude towards her after he returned from abroad. She did not like how he treated her when he tried to act as if she was his wife. Fatma felt he had abused her and wondered whether he would have behaved similarly if her father had been alive. The client felt that people's attitudes had changed after the death of her father, including that of her cousin, who did not respect the death of his uncle or his family. It is clear that Fatma's religious background influenced her way of thinking and her behaviour:

"The cousin I was engaged to ... once he came back from a journey ... he was behaving as if I was his wife ... he wanted to take me for an outing ... he wanted to kiss me ... I feel injured within. ... When my father was alive ... [my cousin] never raised his eyes to watch me ..."

In this session Fatma was aware of the importance of living her life and enjoying it, but was unable to forget the unpleasant past experiences. She started to recall some of her unhappy childhood memories and tried to link them with her present fear of death. It is clear that the client was actively searching within herself for the reasons behind her fears:

"By Allah and thanks to Him ... but I don't know why my mind thinks about my previous experiences. I notice that I have been frightened about some things since my childhood [falls silent]".(Session5)

This session was one of the most important we had. Fatma shared different aspects of her inner self with me and was able to observe her relationships with others from different angles. She was spiritual and calm and able to share her secrets. She was in her own world where she was totally herself and enjoyed her spiritual moments without interruption from the external world. Fatma was totally honest and real and shared things with me that she would not be able to talk about or even mention to her husband:

"I think I've started describing myself better ... I'm able to recognize myself now ... in these sessions with you I've started to know the source of the fear ... The fear is due to some particular reasons and events in my life. I thought that I would tell everything in the first session, and get the solutions from the first session ... I realized that I have in myself many things which need to be revealed".(Session6)

In sessions 7 and 8 Fatma shared her feelings with me about her miscarriage and its effect on her life. She looked squeezed and unhappy. Even though she was feeling better at her seventh session and talked more positively about her relationship with herself, at this session she felt as if she had lost all the positive changes that she had achieved in her previous sessions.

"Earlier I used to feel alive ... I loved greenery ... loved poems ... but all these things have gone ... I feel that life is tasteless now".

She was aware of not being able to face the present and of wanting to live in the past, as her childhood had been the happiest period in her life:

"Live in the present ... but due to the fear, I don't want to face the present ... I don't want to forget my childhood". (Session 9)

The last session we had illustrates the positive improvement in the client's case. She was active and willing to do the things that she used to enjoy. I believe this indicated the changes within her that affected her whole life positively and made her feel alive. This session showed the client's commitment to move on with her life. She also became aware of the value of remembering the good things in her past rather than engaging herself with unhappy memories:

"Reading, for example, there are things I love books I love. I love romantic things very much, like poems, I find myself very much in these things".

Fatma was aware of the effect of her depression on her relationship with the self. She was able to associate her psychological illness with her self loss:

"I found that I was losing [myself], maybe the depression is the reason ... I've found [myself] Maybe I lost her because of the depression. My self is back and now I'm able to do my duties at home. I used to live in darkness".(Session 14)

Fatma described how she had become aware of losing herself. She realized the importance of having treatment to help her cope with her illness: 
"I discovered that Fatma is missing ... the reason was that I was tired and unable to find myself ... I had lost hope in the present I am living in ... I felt that I had really been in need of such treatment for a long time ... maybe twenty years". (Feedback 1)

A wonderful and touching statement by Fatma shows the depth of the therapeutic relationship I managed to establish with her:

"My understanding of family was my husband and my children, and now Doctor Elnour (the HMC psychologist) and Doctor Aisha (me) are both in my family".

The client also stated:

"I was glad to come to the sessions. I call it the journey of finding oneself". (Feedback 2)

According to Rogers, a client needs to be helped by the cousellor to feel safe and not judged in the counselling session. Rogers (1961) states:

"I find that the more accepting and liking I feel toward this individual, the more I can be creating a relationship that he can use. By acceptance I mean a warm regard for him as a person of unconditional self-worth, of value no matter what his condition, his behaviour, or his feelings. It means a respect and liking for him as a separate person, willingness for him to possess his own feelings in his own way. It means an acceptance of and regard for his attitudes of the moment...." (p.34).

\section{Beck Depression Inventory scoring}

According to Beck Depression Inventory (BDI) form that Fatma has filled before and after the treatment, she moved from being severely depressed with a score of 39 to moderately depressed with a score of 19, a drop from severe to moderate depression.

This indicates how effective the sessions were. The sessions helped Fatma to think positively about herself and others .Her change helped her to move on and accept others as they are .Fatma became less self-critical and able to feel safe and protected .She began to look at the current life situation more closely .She realized that her children needed her . She became more relaxed and satisfied. She felt less tense about her problems because was able to face them and deal with them .Religious support was crucial for a person such as Fatma because she liked to relate everything to Allah .Fatma linked all her changes and improvements to Allah first and then to the counseling support. Undoubtedly religious support was an important factor in making the counseling work, as supported by Cooper's research summary [4]:

"What about matching on beliefs and values; would a client who holds conservative values, for instance, do better with a therapist of a similar outlook, or would they do just as well with a therapist with a liberal worldview? Research on this question, as one might expect, is relatively sparse, but one aspect of it that has been researched in some depth is that of the effect of a convergence of religious and spiritual values in therapy and counseling". (pp. 84-85)

I believe the positive outcome of Fatms's case is not only based on me as a person, but also applying the modification of PCA adapted to the Islamic and cultural background of both the client and the counselor.

The feedback highlighted the importance of building a healthy therapeutic relationship and this agrees with Wilkins [5] point of view when he states that

The person-centered approach emphasizes the importance of the therapeutic relationship between the counselor and the client and the active use of that relationship to highlight and explore aspects of the client's social and emotional functioning which are manifested in the therapeutic relationship (p.55).

Overall I will end the article by a description to the end of the counseling process by Fransella and Dalton [6] below in a way that reflects my experience of Fatma's sessions ending:

The client becomes less dependent on the counselor and sets up his own more spontaneous experiments. His world widens and his energies are directed more variously ... There is a move away from the client's 'problems' and his immediate personal concerns into a more dilated field of interests. Finally he really 'hasn't time' to come any more ... life is too full. (p.145).

\section{References}

[1] Gilbert, P., (2000), Overcoming Depression: A SelfHelp Guide Using Cognitive Behavioural Techniques. London: Constable \& Robinson Ltd.

[2] Baldwin, M., (2000), The Use of Self In Therapy, Second Edition, Routledge.

[3] British Association for Counselling Psychology, (2008), 'What is Counselling?' http://www.bacp.co.uk.

[4] Cooper, M., (2008), Essential Research Findings in Counselling and Psychotherapy. London: Sage Publications.

[5] Wilkins, P., (1999), The Relationship in PersonCentred Counselling, in Understanding the Counseling Relationship, Feltham.C, sage publication, UK.

[6] Fransella, F. and Dalton, P., (2000), Personal Construct: Counselling in Action. London: Sage Publications. 